\title{
Análise dos elementos paratextuais do manual de aritmética Taboada Curiosa (Portugal, século XVIII)
}

\author{
Analysis of the paratextual elements of the manual of arithmetic Taboada Curiosa \\ (Portugal, 18th century)
}

\author{
Fernando Ripe ${ }^{1}$ \\ Antônio Maurício Medeiros Alves ${ }^{2}$
}

\begin{abstract}
Resumo
Este artigo apresenta uma análise, sob a perspectiva da História da Educação (e) Matemática, dos elementos paratextuais que compõem as instruções educativas para o ensino da aritmética presentes no manual pedagógico Taboada Curiosa, de autoria do espanhol Joam Antonio Garrido. Publicada inicialmente no ano de $1737 \mathrm{em}$ Lisboa, a obra tinha por objetivo instruir na arte de contar e escrever por meio das regras que se aplicavam nas "boas Escolas" do Reino de Portugal. Consideramos que Taboada Curiosa foi um impresso de relativo sucesso editorial no contexto do setecentismo português, tornando-se um eficiente mecanismo pedagógico para a construção de significados aritméticos. Centraremos nossa análise nos elementos periféricos que compõem o impresso, sobretudo no frontispício, nos agradecimentos, no prólogo e no sumário, destacando como o professor de aritmética Joam Garrido estabeleceu estratégias discursivas de direcionamentos de leitura aos seus potenciais consumidores da obra.
\end{abstract}

Palavras-chave: História da Educação, Manual de Aritmética, Século XVIII.

\begin{abstract}
This article presents an analysis, under the perspective of the History of Education (e) Mathematics, of the paratextual elements that compose the educational instructions for the teaching of arithmetic present in the pedagogical manual Taboada Curiosa, written by the Spanish Joam Antonio Garrido. Initially published in 1737 in Lisbon, the work was intended to instruct in the art of counting and writing through the rules that have been applied in the "good Schools" of the Kingdom of Portugal. We consider that Taboada Curiosa was a form of relative editorial success in the context of the seven hundred Portuguese, becoming an efficient pedagogical mechanism for the construction of arithmetic meanings. We will focus our analysis on the peripheral elements that make up the printed, especially in the frontispiece, thanks, the prologue and the summary, highlighting how the arithmetic professor Joam Garrido established discursive strategies of reading directions to his potential consumers of the work.
\end{abstract}

Keywords: History of Education, Arithmetic, Manual, 18th century.

\section{Submetido em: 28/08/2020 - Aceito em: 30/09/2021 - Publicado em: 12/11/2021}

${ }^{1}$ Doutor em Educação pela Universidade Federal de Pelotas (UFPel). Professor da Faculdade de Educação (FaE) e do Programa de Pós-graduação em Educação Matemática (PPGEMAT) da Universidade Federal de Pelotas (UFPel), Brasil. E-mail: fernandoripe@yahoo.com.br. ORCID: http://orcid.org/0000-0003-0007-0597

${ }^{2}$ Doutor em Educação pela Universidade Federal de Pelotas (UFPel). Professor da Faculdade de Educação (FaE) e dos Programas de Pós-graduação em Educação Matemática (PPGEMAT) e em Ensino de Ciências e Matemática (PPGECM) da Universidade Federal de Pelotas (UFPel), Brasil. E-mail: alves.antoniomauricio@gmail.com. ORCID: https://orcid.org/0000-0001-5857-4283 


\section{Introdução}

Os estudos relativos aos campos da História da Educação (e) Matemática, e seus distintos modos de se perceber o processo educativo de determinadas épocas nos colocam frente a inúmeras possibilidades de observação e de pesquisas. Cabe, então, ao pesquisador destes campos, ampliar as condições de visibilidade sobre os processos que constituíram as práticas educativas escolares e não-escolares de Matemática, que na dinâmica temporal se materializaram em discursos e práticas acerca do seu ensino. Vale ressaltar que para o historiador em Educação Matemática Wagner Valente (2005), a pesquisa em História da Educação Matemática está inscrita no campo da História, e mais especificamente, ela deve se reportar ao campo da História da Educação.

Consideraremos neste estudo como definição para paratexto, a partir de Genette (2009), toda e qualquer parte textual ou gráfica que, de algum modo, mantenha uma relação estratégica com o texto correspondente de uma obra. Seja para caracterizar sua legitimação, seja para influenciar a leitura ou interpretação, os paratextos se constituem como elementos tácitos do autor e/ou editor da obra. Elementos preliminares, como capa, título, licenças, frontispício, sumário, dedicatória, prólogo, etc., adquirem valiosa importância para os estudos históricos, tanto como fonte documental como elementos de análise, pois representam, dentro de um sistema coletivo de símbolos, as possíveis relações e significações estabelecidas entre autores e editores com os potenciais leitores. Os dados que aqui serão analisados reiteram a importância do leitor evidenciada nos paratextos e destacam possíveis ligações entre o autor e o leitor, firmando, assim uma possibilidade de fidelidade entre eles.

Será a partir da perspectiva destes dois campos de pesquisa, da História da Educação (e) Matemática, que nossa investigação estará centrada. Assim, o presente artigo tem por objetivo identificar e analisar quais foram as estratégias discursivas ${ }^{3}$ que o mestre de aritmética Joam Antonio Garrido se valeu para escrever na primeira metade do século XVIII o manual de aritmética Taboada Curiosa. Partindo deste objetivo, este texto foi organizado da seguinte maneira: primeiro, analisamos como o verbete arismetica foi definido no contexto português setecentista. $\mathrm{O}$ exame etimológico possibilita indicar em que medida os saberes matemáticos eram compreendidos em uma determinada e datada sociedade. Identificamos, também, uma série de obras impressas nos séculos imediatamente anteriores ao XVIII que versavam sobre aritmética. Tal levantamento nos confere a possibilidade de identificar o cumprimento dos mestres de um "típico" método de ensino da matemática. Evidente que esta tipificação metodológica também estará presente nos manuais pedagógicos

\footnotetext{
${ }^{3}$ Compreende-se a produção de sentido da recepção, por meio de condições determinadas sócio-históricas, na medida em que, quando lemos estamos atribuindo significações a partir de um lugar social e com direcionamento histórico (Orlandi, 1999, p. 102). Não obstante, o funcionamento de estratégias discursivas na autoria nas produções de sentido de um texto se dá de forma regrada, regida por ordens que definem o que se pode e se deve dizer e as maneiras de se enunciar, pois, "[...] em toda a sociedade a produção do discurso é ao mesmo tempo controlada, selecionada, organizada e redistribuída por certo número de procedimentos que têm por função conjurar seus poderes" (Foucault, 1996, p. 8).
} 
setecentistas. Por isso, construímos um quadro com as principais obras direcionadas ao ensino do ler, escrever e contar que foram impressas no século XVIII; segundo, identificamos como o autor da referida obra privilegiou determinados conhecimentos matemáticos, vistos como necessários para o processo educativo dos sujeitos lusitanos no período. Para tanto, apresentamos aspectos da materialidade da obra, o número de edições e alguns elementos paratextuais (frontispício, dedicatória, licenças, agradecimentos, prólogo e prefácio) presentes no livro de Garrido que procuravam justificar e anunciar previamente um sucesso no mercado editorial ao longo do século XVIII.

\section{Arismetica ou Da arte de contar: perspectivas e contextos históricos para seu ensino}

A análise etimológica do vocábulo aritmética revela que sua derivação ocorre do grego arithmétiké, que significa arte de contar e de arithmos que traduz a ideia de número. $\mathrm{O}$ léxico assume significado semelhante em latim, pois arithmetica também indica a arte de contar. No campo lexicográfico português arismética ou aresmética são vocábulos arcaicos, cujo usos impressos para o processo de ensino datam do século XVI.

De acordo com o levantamento realizado por Almeida (1992, v. 1, p. 67), o termo arismética consta no frontispício de impressos nos séculos XVI e XVII dos seguintes autores portugueses: Gaspar Nicólas (1519, 1530, 1541, 1559, 1573, 1590, 1594, 1607, 1613, 1679); Ruy Mendes (1540); Bento Fernandes (1555), Gaspar Cardoso de Sequeira (1612, 1626, 1651, 1675, 1686) e Afonso Guiral e Pacheco (1624).

No século XVIII português impressos matemáticos como o do comerciante da cidade do Porto, Afonso de Villafanhe Guiral e Pacheco, ganham sistemáticas reedições. Tal importância deve-se, sobretudo, ao fato de que a resolução de problemas sociais, geralmente associados às medidas e às grandezas, são convertidos para uma prática de cálculo escrito de cunho escolarizado. Nesse sentido que "os saberes matemáticos operados em manuais destinados à educação estão imersos em um longo processo histórico de alfabetização da população, marcado por relações ligadas ao contexto social de uso do número" (Amaral \& Ripe, 2017, p. 251).

No século XVIII a expansão das casas tipográficas e o evidente progresso das práticas de escolarização em Portugal foram condições de possibilidade para que a impressão de livros pedagógicos ganhasse usos e circulasse por específicos grupos sociais, sejam os urbanos ou mais abastados que pretendiam ter uma educação mais próximas aos padrões da Corte lusitana. Jean Hébrad (1989, p. 63) assinalou para o caso das "pequeñas esculeas" do Antigo Regime francês, que a instrução não ia além de uma limitada alfabetização acompanhada necessariamente de uma instrução religiosa cristã. Para o historiador francês Hébrad (1989, p. 63)

[...] los saberes enseñados parecían ser entonces, más que disciplinas, diferentes facetas de las prácticas ordinárias de la cultura escrita, concebida indistintamente 
DOI: $10.20396 /$ zet.v29i00.8661083

como soporte de la doctrina religiosa o como instrumento necesario para la gestión de su vida y sus asuntos, por triviales que fuesen.

Contudo, não se trata exclusivamente da proliferação da escolarização do século XVIII, pois a publicação de certos conhecimentos científicos do seiscentismo ou quinhentismo português como a navegação astronômica, a mecânica e os cálculos de negócios, criaram emergências aritméticas mais complexas, promovendo seu desenvolvimento.

As acepções dicionarísticas de arithmetica, no século XVIII português, a definem como "arte de calcular por algarismos" (Silva, 1789, p. 179) ou como "arte de contar, cujas regras principaes constituem em somar, diminuir, multiplicar, repartir, \&c" (Bluteau, 1728, p. 496). Tendo em vista que a concepção de arte, presente nas duas acepções, refere-se, neste período, a ideia de método e regras, podemos evidenciar que a aritmética se constituiu fundamentalmente por uma prática regrada (Ripe, 2017, p. 146).

No setecentos luso uma série de impressos buscavam dar conta do ensino das primeiras letras. Tal processo estava, em muito, relacionado com a aprendizagem da leitura, da escrita, da contagem ou, para os mais habilidosos, da aritmética, da incorporação da doutrina cristã e dos regimes de civilidade. ${ }^{4}$ A aprendizagem da leitura se constituía como uma prática essencial nas escolas elementares. Não obstante, os níveis de leitura, escrita e cálculos eram coeficientes de distinção social. A idade para a criança iniciar na leitura poderia variar de acordo com o método de ensino a ser seguido, cuja maioria indicava a idade dos sete anos, ou pela insistência de um mestre em particular.

De modo geral os compêndios que instruíam a aprendizagem da escrita recomendavam que a habilidade no traço só deveria ser iniciada após o discípulo ter pleno domínio da leitura. Observa-se que:

A criança só devia iniciar-se na escrita depois de saber ler desembaraçadamente toda a letra impressa e quando possuísse alguma firmeza na mão, de cujos movimentos depende a formação das letras; uma mão débil e pouco firme, em vez de letra, forma 'garatujas e gregotins', habituando-se a eles e perdendo o jeito para a boa forma dos caracteres (Adão, 1997, p. 229).

Ao lado, e na mesma medida, da leitura, escrita e contagem estavam a aprendizagem da doutrina cristã que juntamente com os domínios das regras de civilidade, compunham a devida formação de um futuro "cidadão" português. As instruções do catecismo cristão estavam previstas desde a entrada da criança no ambiente de escolarização. Ainda mesmo sem saber ler, a criança deveria aprender de cór as principais orações (Pai Nosso, Ave Maria, Credo e Confissão) e os Mandamentos da Lei de Deus e da Igreja (Adão, 1997, p. 235). No processo de aprendizagem do catecismo era estimulado que o discípulo desenvolvesse o

\footnotetext{
${ }^{4}$ Observa-se que esta proposição didática não se afasta da ideia de quadrivium (os quatro caminhos ou vias), uma vez que estabelece um de quatro matérias ensinadas na fase inicial do percurso educativo. Sugere-se como leitura Aranha (2006).
} 
DOI: $10.20396 /$ zet.v29i00.8661083

hábito da memorização. Por meio de perguntas e respostas o aluno era estimulado a decorar "palavras difíceis e abstrações, exigindo-se uma repetição mecânica de frases sem que da parte dele existisse uma compreensão ou interiorização do conteúdo" (Adão, 1997, p. 235).

O ensino das regras de civilidade, sinteticamente, consistia na aprendizagem de um conjunto de convenções que regiam socialmente o modo como os sujeitos deveriam se comportar. Nestes manuais e compêndios procuravam-se ditar a formatação de uma disciplina pessoal, uma específica forma como a criança deveria controlar suas atitudes e gestos, sempre contidos e adequados ao ambiente.

No que se refere aos manuais que ensinavam a aritmética, a maioria permanecia fiel ao modelo de ensino proposto por Gaspar Nicólas do século XVI. Contudo, algumas mudanças podem ser conferidas no quadro específico das realidades, ou seja, dos contextos sociais do uso dos números. Se, por um lado, o ensino da aritmética permanece guiado pela contínua imitação por meio de exaustivas exemplificações, por outro, os problemas relativos às medidas e às grandezas são adaptados pelas práticas sociais que "refletem certas formas particulares de progresso técnico e de avanço da sociedade portuguesa" (Almeida, 1992, v. 2, p. 7).

A partir do estudo realizado pela historiadora da educação Áurea Adão (1997) constituímos um quadro relacionando os principais autores que publicaram manuais relativos ao ensino da aritmética ao longo do século XVIII português.

Quadro 1 - Relação de manuais pedagógicos publicados em Portugal (século XVIII)

\begin{tabular}{|c|c|c|}
\hline Autor & Ano de Edição & Obra \\
\hline $\begin{array}{l}\text { Figueiredo, Manuel de } \\
\text { Andrade de }\end{array}$ & 1722 & $\begin{array}{l}\text { Nova escola para aprender a ler, escrever, e } \\
\text { contar..., Lisboa Occidental: Na Offic. de Bernardo } \\
\text { da Costa de Carvalho. }\end{array}$ \\
\hline Garrido, Joam Antonio & 1737 & $\begin{array}{l}\text { Taboada curiosa, novamente reformada, e } \\
\text { argumentada... Lisboa: Offic. Offic. de Rita } \\
\text { Cassiana. }\end{array}$ \\
\hline Oliveira, Francisco de & 1739 & $\begin{array}{l}\text { Arithmetica verdadeira, ou arte facilíssima de } \\
\text { contar... Porto: Ed. Autor. }\end{array}$ \\
\hline $\begin{array}{l}\text { Pereira, Francisco de } \\
\text { Queiroz }\end{array}$ & 1749 & $\begin{array}{l}\text { Compendio arithmetico, obra muito util para } \\
\text { principiantes aprenderem com facilidade... Coimbra: } \\
\text { Real Colegio das Artes. }\end{array}$ \\
\hline $\begin{array}{l}\text { Silva, Leonor Thomazia } \\
\text { de Souza e }\end{array}$ & 1756 & Escolla nova christã, e politica..., Lisboa: 1756. \\
\hline \multirow[t]{3}{*}{$\begin{array}{l}\text { Rego, Jozé Antonio da } \\
\text { Silva }\end{array}$} & 1774 & $\begin{array}{l}\text { Dialogo da Arithmetica, em que se explicão as } \\
\text { quatro espécies de contas, e se toca a Astronomia... } \\
\text { Lisboa: Offic. da Viuva de Ignacio Nogueira Xisto. }\end{array}$ \\
\hline & & $\begin{array}{l}\text { Taboada para a numeração. Para uso das Escolas de } \\
\text { N. S. das Necessidades. Manuscrito, com licença para } \\
\text { impressão em 09.11.1777. }\end{array}$ \\
\hline & & Escola fundamental, ou methodo facil para aprender \\
\hline
\end{tabular}


DOI: 10.20396/zet.v29i00.8661083

\begin{tabular}{|c|c|c|}
\hline & & $\begin{array}{l}\text { a ler, escrever, e contar..., 1807. Autorizada a } 1^{\text {a }} \\
\text { edição em } 25.02 .1779 .\end{array}$ \\
\hline & & $\begin{array}{l}\text { Elementos de Arithmetica ou regras de numeração } \\
\text { (...) para uso das primeiras escolas. Manuscrito, com } \\
\text { licença de impressão em } 10.04 .1783 \text {. }\end{array}$ \\
\hline \multirow[t]{2}{*}{$\begin{array}{l}\text { Souza, Pe. Manoel Dias } \\
\text { de }\end{array}$} & 1784 & $\begin{array}{l}\text { Nova escola de meninos. Na qual se propõem hum } \\
\text { methodo facil para ensinar a lêr, escrever, e contar, } \\
\text { com huma breve direção para a educação dos } \\
\text { meninos. Ordenada para descanço dos Mestres, e } \\
\text { utilidade dos Discipulos. Coimbra: Na Real Officina } \\
\text { da Universidade }\end{array}$ \\
\hline & 1784 & $\begin{array}{l}\text { Argumento em forma de dialogo, introduzindo dous } \\
\text { Estudantes: Hum que diz não haver necessidade de } \\
\text { Arithmetica, e tem por opinião, que não ha ninguém } \\
\text { que não saiba contar, tendo dinheiro; e o outro } \\
\text { defende o contrario. Lisboa: Offic. de Francisco Luiz } \\
\text { Ameno. }\end{array}$ \\
\hline $\begin{array}{l}\text { Vasconsellos, Anna } \\
\text { Sylveira de }\end{array}$ & & $\begin{array}{l}\text { Escóla nova ou tesouro de meninos, em diálogo entre } \\
\text { huma sabia May e seu filho. Manuscrito, com licença } \\
\text { de impressão em 07.07.1785. }\end{array}$ \\
\hline \multirow[t]{2}{*}{ Sá, Manuel de } & & $\begin{array}{l}\text { Taboada geral, ou noçoens preliminares da } \\
\text { Arithmetica. De novo recompilada pelo methodo } \\
\text { Socratico, ou dialogístico para a Instrucão da } \\
\text { Mocidade Portugueza. Manuscrito, com licença de } 3^{\text {a }} \\
\text { impressão em 18.02.1788. }\end{array}$ \\
\hline & 1789 & $\begin{array}{l}\text { Conferencia literária, dividida em doze liçoens. Nas } \\
\text { quaes se dá aos meninos, que frequentão a escola } \\
\text { huma breve, e bem limitada idêa geral de Gramatica } \\
\text { Portugueza, e das partes de que consta; e tambem da } \\
\text { Arithmetica, e Doutrina Christã. Composta por um } \\
\text { professor de Lingua Portugueza. Para uso de seus } \\
\text { Discipulos. Porto: Offic. de Bernardo Antonio } \\
\text { Farropo \& C. }{ }^{\text {a. }}\end{array}$ \\
\hline \multirow[t]{2}{*}{$\begin{array}{l}\text { Viterbo, Fr. Antonio de } \\
\text { Santa Rosa de }\end{array}$} & & $\begin{array}{l}\text { Proposições de principios fundamentais } \\
\text { d'arithmetica, que publicamente, na Igreja do Real } \\
\text { Collegio do Espirito Santo da Cidade d'Evora, no } \\
\text { dia } 26 \text { de Maio de 1790, defendêrão sete meninos da } \\
\text { Escola Regia do mesmo Collegio... Lisboa: Offic. de } \\
\text { Simão Thaddeo Ferreira, s.d. (com licença de } \\
\text { impressão em 19.08.1790). }\end{array}$ \\
\hline & 1794 & $\begin{array}{l}\text { Methodo facil de aprender a contar, em que se } \\
\text { explica todo o gênero de contas juntamente com a } \\
\text { sua razão, uso, e demonstração... Lisboa: Offic. de } \\
\text { Simão Thaddeo Ferreira. }\end{array}$ \\
\hline Barbosa, Jerónimo Soares & 1796 & $\begin{array}{l}\text { Eschola popular das primeiras letras, dividida em } \\
\text { quatro partes. Parte quarta. Arithmetica vulgar. } \\
\text { Coimbra: Real Imprensa da universidade. }\end{array}$ \\
\hline
\end{tabular}


Fonte: Quadro elaborado a partir de ADÃO (1997).

Os discursos pedagógicos portugueses da segunda metade do século XVIII, em grande medida, estavam influenciados pelo gerenciamento político pombalino. Foi por meio da promulgação da Carta Régia de 6 de novembro de 1772, que os mestres foram responsabilizados a ministrarem nas escolas régias de primeiras letras o ensino de ler, escrever e contar, em combinação com o catecismo e com as regras de civilidade (Carta, 1772, p. 291).

Nesses manuais existe uma tendência em indicar aos mestres a função de desenvolverem atividades educativas relacionadas à formação moral da criança e à aquisição de conhecimentos. Vale destacar que a "boa educação", neste contexto, é recorrentemente referida como a inserção de costumes relativos aos bons cristãos para que na idade da razão possibilitem o bem da República (Adão, 1997). Todavia, também se alertava para que as instruções não se restringissem à simples memorizações do discípulo, transformando-o em um "confuso armazém de factos". O ensino dos mestres aos discípulos deveria ser ordenado para "aclarar as noções que correspondem aos mais vulgares termos, em acostumá-los a distingui-las bem, e a conhecer exatamente as proporções, e analogias, que umas conservam com as outras" (Villeneuve, 1767, p. 98). ${ }^{5}$

No que se refere à aprendizagem da aritmética, os manuais alertam que os discípulos só aprenderiam a realizar contagens e as outras "espécies de contas" após terem o pleno domínio da leitura e da escrita. Nesse sentido, o ensino da aritmética corresponderia ao nível final da instrução elementar. Portanto, ter domínio dos procedimentos de contagem e de cálculos (operações aritméticas), em uma sociedade moderna que pretendia ser civilizada e alfabetizada (principalmente nos ambientes de leitura), poderia indicar certa distinção social.

Dentre os manuais pedagógicos (conforme o quadro 1) que descrevem o ensino da aritmética, um deles obteve relativo sucesso editorial ao longo do setecentos português. Trata-se da obra de Taboada Curiosa, composta por três partes e acrescida de várias curiosidades relativas ao campo numérico e à aprendizagem da escrita. No primeiro capítulo o professor de aritmética Joam Antonio Garrido apresenta a definição de peso, conta e medida. De acordo com o autor, estas definições são necessárias para apresentar "as regras geraes, de que se formão todas as contas, e mais toda a variedade de moedas, que concorrem neste Reyno, e outros da Europa" (Garrido, 1752, p. 01).

\section{Taboada Curiosa: análise sobre os elementos paratextuais}

Os livros de aritmética que circularam na Europa no período moderno eram produzidos a partir de problematizações e experiências advindas do campo dos negócios e das necessidades de mercadores. Além dos aspectos mercantilistas, os manuais aritméticos à

\footnotetext{
${ }^{5}$ Uma análise mais minuciosa sobre os modelos de ensino dos mestres de ler, escrever e contar foi descrita por Áurea Adão na primorosa obra Estado Absoluto e ensino das primeiras letras (1997).
} 
grosso modo também “determinam e esclarecem progressos de cálculos e impõem critérios algorítmicos" (Almeida, 1992, v. 2, p. 06).

A estrutura interna destes livros de aritmética denotava, em sua maioria, relativa homogeneidade, pois apresentavam aspectos que se repetiam como, por exemplo, os elementos paratextuais. Na sequência, a apresentação do conceito de aritmética como sendo uma arte, em conseguinte a aprendizagem da leitura dos números. Áurea Adão (1997, p. 257) chama a atenção para o fato de ser "por meio da escrita e do estudo da tabuada, [que] os alunos começavam a saber de cor os algarismos". Garrido oferecia como etapa seguinte de aprendizagem a numeração romana, porém essa sequência não era consensual, visto que alguns autores optavam por deixá-la para mais tarde. Condição fundamental para o "bom" aluno era o domínio das espécies de contas, sejam a adição, diminuição, multiplicação e a divisão, também chamada de repartição. $O$ ensino das espécies era realizado por meio de exemplificações. Raramente, nestas etapas, era proposto como método de ensino a resolução de problemas para aplicar as operações matemáticas em estudo. Isto posto, era o momento de ensinar - somente aos mais habilidosos - os conteúdos, que de modo geral estavam muito associados com o domínio da ideia de grandezas. Será o desenvolvimento dos conteúdos aritméticos, definidos por aplicações relativas à peso, contagens e medidas, que o manual será propriamente elaborado e que completa o desejo manifesto pelo autor no frontispício da obra. Assim era descrito que o manual fosse para "que se trata de todas as regras geraes, e especies de conta, que deve saber hum bom contador para o trato, e cõmercio deste Reyno, e de todo o mundo, com outras curiosas, e utilissimas noticias, que vão no sim, fundadas sobre os numeros da conta" (Garrido, 1752, Frontispício).

Sobre o autor de Taboada Curiosa poucas são as informações que detemos. Sabe-se, pelo Diccionario Bibliographico Portuguez (1859, p. 290) de Innocencio Francisco da Silva (1810-1876), que João [Joam] Antonio Garrido era "natural de los Cameros, povoação do reino de Hespanha; d'onde vindo para Lisboa, residiu aqui muitos anos, exercendo a profissão de Mestre de Arithmetica e Escripta". Innocêncio da Silva indicava conhecer duas obras de Garrido, seja o próprio manual de aritmética que se encontrava na quinta reimpressão e um livro de agricultura, ${ }^{6}$ também reimpresso diversas vezes. Porém, Silva não poupava críticas ao mestre Garrido e afirmava tanto desconhecer as versões anteriormente impressas, como rejeitava a qualidade dos textos que compunham suas obras.

Estas obras nada têem que as recomende; a própria linguagem em que são escriptas é tal, que o collector do chamado Catalogo da Academia as deixou no escuro, não the merecendo credito, nem ao menos no que diz respeito ás vozes facultativas que n'ellas se empregam (Silva, 1859, p. 290).

De fato, a obra Taboada Curiosa recebeu pouca atenção no século XIX, tendo apenas uma edição impressa no ano de 1815 , mas como podemos observar no quadro a seguir, em

\footnotetext{
${ }^{6}$ A saber: Garrido, J. A. (1814). Livro de Agricultura, em que se tracta com clareza e distincção o modo e tempo de cultivar as terras de pão, vinho, azeite, hortaliças, flores dos jardins, e pomares de fructa; como tambem da creação dos animaes domésticos, e da caça dos bravios. Com muitos segredos e importantes avisos, etc., etc. Lisboa: Imprensa Regia.
} 
DOI: $10.20396 /$ zet.v29i00.8661083

que catalogamos as diferentes reimpressões do manual aritmético, a obra de Garrido foi de relativo sucesso editorial no reino português durante os três quartos finais do século XVIII. Circulando especialmente na cidade de Lisboa, onde era impressa e vendida.

Quadro 2 - Relação das edições que foram possíveis de catalogar da obra Taboada Curiosa

\begin{tabular}{|c|c|l|l|}
\hline Edição & $\begin{array}{c}\text { Ano de } \\
\text { Publicação }\end{array}$ & Cidade & Editora e/ou local de venda \\
\hline $1^{\text {a }}$ & 1737 & Lisboa & Offic. de Rita Cassiana \\
\hline $2^{\text {a }}$ & 1739 & Lisboa & $\begin{array}{l}\text { Vende-se na Escola da rua dos canos, e em outras do bairro } \\
\text { alto. }\end{array}$ \\
\hline $3^{\text {a }}$ & 1747 & Lisboa & Officina de Domingos Rodrigues \\
\hline $4^{\text {a }}$ & 1752 & Lisboa & $\begin{array}{l}\text { Officina de Domingos Rodrigues. Vende-se este livro na } \\
\text { mesma Offic., em casa do Autor e debaixo dos arcos do } \\
\text { Rocio. }\end{array}$ \\
\hline $5^{\text {a }}$ & 1759 & Lisboa & $\begin{array}{l}\text { Ignacio Nogueira Xisto. Vende-se na mesma Officina, no } \\
\text { principio da Rua dos Cavalleiros. }\end{array}$ \\
\hline $6^{\text {a }}$ & 1772 & Lisboa & Off. da Viuva de Ignacio Nogueira Xisto \\
\hline $7^{\text {a }}$ & 1788 & Lisboa & Officina de Francisco Borges de Sousa \\
\hline $8^{\mathbf{a}}$ & 1814 & Lisboa & Imprensa Regia \\
\hline
\end{tabular}

Fonte: Quadro elaborado pelos autores.

De acordo com o frontispício da edição que estamos analisando (ver Figura 1), no pé da página é possível identificar que o manual pedagógico possuía a autorização para impressão e todas as licenças necessárias, sendo seu comércio realizado no interior das próprias escolas de primeiras letras da cidade de Lisboa. Neste caso, poder-se-ia inferir que o número de impressos regulasse com o número de alunos que frequentavam tais escolas. Decerto é que podemos denotar que se tratava de um impresso pedagógico bem recebido pelo público, pois teve, pelo menos, oito edições em diferentes casas tipográficas de Lisboa ao longo de quase cem anos, o que era algo bem incomum para livros pedagógicos. 


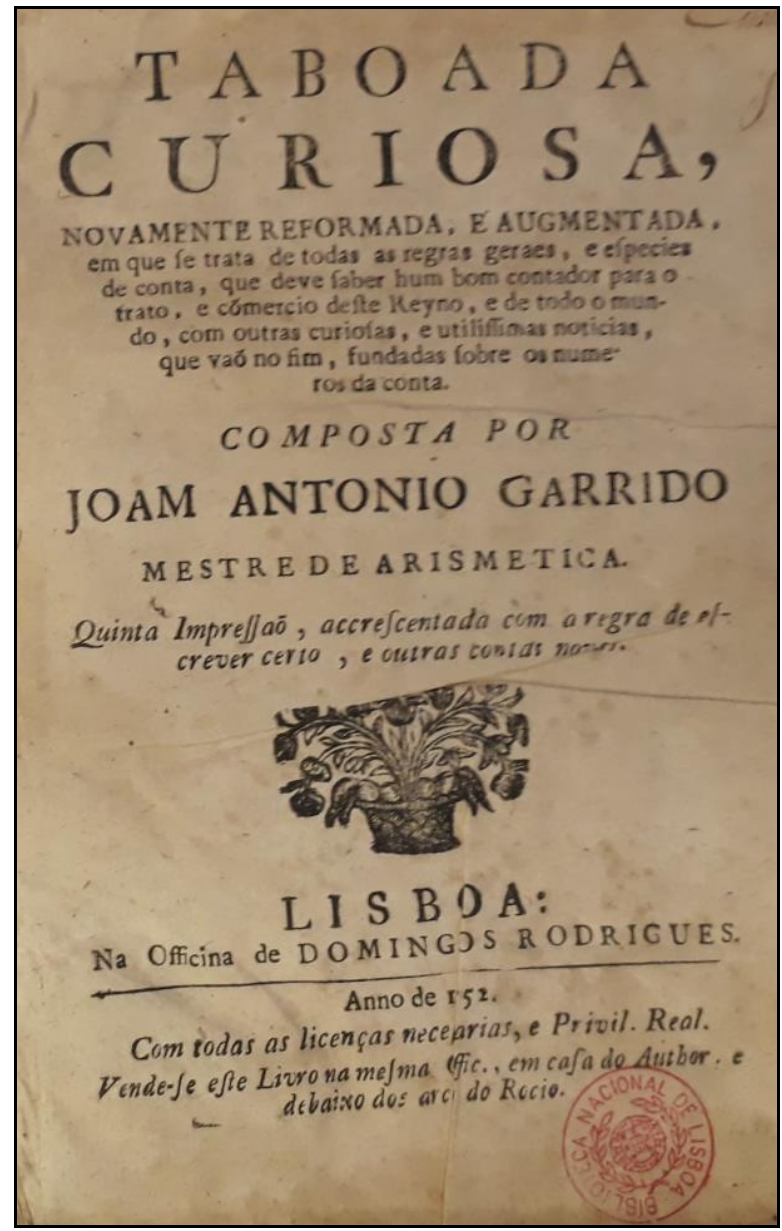

Figura 1 - Frontispício da obra Taboada Curiosa Fonte: Garrido (1752).

Tivemos acesso a duas edições da obra. A primeira, em sua versão digital, datada de 1739 - cujo acesso está disponível no banco de dados digitais da Google books; ${ }^{7}$ a segunda, publicada no ano de 1752, trata-se de uma versão impressa disponível para consulta na Biblioteca Nacional de Portugal (BNP). Adotaremos como objeto de análise a última por se tratar de uma edição "novamente reformada, e augmentada" (Garrido, 1752).

No prólogo da obra o professor de aritmética Garrido pretende apresentar todo o “conteúdo [...] do Livro ao Leitor". Como forma de aproximação entre autor e leitor, Garrido justifica o método de ensino que compõe Taboada Curiosa. Nas palavras de Garrido (1752, Prólogo):

Suppondo, amigo leitor, que todas as Artes constão de certas regras, ou partes, que juntas constituem hum todo; e supondo, que as partes em que se funda a Arismetica, são números, pezo e medida, tudo coligado com a Taboada universal para formar toda a espécie de conta, certo he que estas partes deves saber distintamente quem quizer ser bom contador.

\footnotetext{
${ }^{7}$ Disponível em: https://books.google.com.br/book acesso em 04 de janeiro de 2018.
} 
O título da obra Taboada Curiosa já indica o método que seu autor priorizou. A composição de "taboas" designa que o ensino será composto por um conjunto de regras sistematizadas em tabelas e quadros, os quais o discípulo "curioso" deveria consultar constantemente, até que possivelmente as decorasse. Por exemplo,

Posto que nenhum contador sabe, quando aprende, de qual conta terá mayor uso, e necessidade, convém que saiba todas; e tambem pela grande união, e dependencia, que humas contas tem das outras, como aqui se verão explicadas com seus exemplos de cada espécie, segundo a experiencia nos tem mostrado, e se pratíca em todas as boas Escólas (Garrido, 1752, Prólogo).

Outro importante elemento presente nos paratextos dos impressos portugueses modernos são as justificativas que os autores descrevem para a impressão da obra. Garrido deu as seguintes razões para a publicação de seu manual pedagógico:

Posto eu na minha escola para ensinar geralmente a todos, ricos, e pobres, nobres, e plebeos, pequenos, e grandes, o que eu sabia; posto ali tambem para aprender muitas cousas que ignorava, e mas ensinou a experiencia [...] chegarãose a mim varias pessoas adultas, huma com ignorância, e outras com malicia por experimentar o meu saber no discurso de treze anos que tive Escola publica. Perguntando-me varias proposiçoens de conta, como aqui apontarey algũas, para que com ellas se provem os novos Contadores (Garrido, 1752, Prefácio).

Tais proposições constituem o índice de vinte e sete temas que a obra apresenta. Os temas foram propostos após o autor ter descrito o processo de aprendizagem "todas as espécies de conta", sejam: "somar, diminuir, multiplicar, e repartir", acrescentadas dos seguintes conteúdos matemáticos: "contas com dizimos, juros, regra de tres, companhia, caixarias, raisquadrada, e raiscubica”. Tais conteúdos seriam o suficiente para o ensino aplicado da aritmética. O fato do último capítulo ser direcionado para o ensino das "Regras de escrever certo" - em que se dava o direcionamento da aprendizagem "das letras, com que se escreve, e syllabas, que se formão dellas" (Garrido, 1752, p. 91) - impede que afirmemos que a obra se trata de um manual estritamente aritmético.

Estrategicamente o mestre de aritmética Garrido assenta as doze primeiras proposições para tratar de grandezas matemáticas. Colocadas sempre na forma de problematização. Por exemplo:

I. Perguntou-me certo Doutor: quantos milhões erão 800 contos de reis?

II. Perguntou-me hũa Padeira, a que preço the sahia o alqueire de trigo, comprando o moyo por doze mil reis.

III. Perguntou-me hum Marchante, quanto lhe rendia hũa vaca, que pezava 10 arrobas, vendido o arratel a 48 reis.

IV. Perguntou-me hum Taverneiro, quanto the rendia hũa pipa de vinho, vendida a canada a tostão.

V. Perguntou-me hum Sacristão, quantos cântaros de azeite havia de mister no anno para trez alampadas da sua Igreja, assentando que huma gasta cada dia hum quartilho.

VI. Perguntou-me hum Ourives, quanto importavão trez marcos de prata, e duas outavas de ouro de ley.

VII. Perguntou-me hum Cavalleiro, quanto rendião cada semana, e cada dia 4000 cruzados de renda no anno.

VIII. Perguntou-me hum Italiano quantas legoas erão 30 milhas. 
IX. Perguntou-me hum Impressor a que preço [...] (Garrido, 1752, Índice).

A criação de um índice repleto de problematizações que envolvem os usos sociais dos números - no cotidiano lusitano urbano do setecentos - pode ser percebido enquanto uma estratégia discursiva que seu autor utiliza para convencer, ou talvez, despertar a curiosidade dos potenciais leitores. Nesse sentido, o sumário teria a função de "arrastar" o leitor para dentro da obra. Observa-se, ainda, que no conjunto de problemas enunciados por Garrido, os exercícios aparecem correlacionados com atividades comerciais. Tais condições representam simbolicamente um quadro social de vivência com negócios, compreendido por trocas, permutas, compras e vendas de mercadorias e pela lida com o dinheiro.

De algum modo o que Garrido propunha é que o leitor adquirisse seu livro, não apenas como recurso, mas como guia instrutivo. Podendo ser lido e relido sempre que necessitar das regras ou conferir distâncias, medidas ou grandezas nas atividades profissionais. Notadamente o leitor é convocado a atribuir significado ao que se aprende, uma vez que existe uma clara aproximação entre os objetos matemáticos que se estuda, com as próprias práticas sociais contextualizadas. Deste modo o discípulo deveria reconhecer nos conhecimentos matemáticos as situações do cotidiano.

Acreditava o Mestre de aritmética espanhol Joam Antonio Garrido (na década de 1730 havia sido naturalizado português por "S. Magestade neste Reyno"), que para um livro "sair a publico" deveria ter um "protector". O conhecido professor de contas matemáticas da cidade de Lisboa trazia a público a segunda edição de seu "livro Taboada Curisosa de contas. novamente corregido, e augmentado para luz dos contadores, e beneficio de todas as Escolas", e, portanto, precisava de "hum Protector tão grande como" a "digníssima pessoa de V. Excellencia” D. Valério da Costa de Gouvea (1678-1742). Tratava-se de uma exemplar figura escolhida pelo Mestre Garrido, pois Gouvea ocupava o cargo de vigário geral do patriarcado de Lisboa e havia sido Desembargador do Paço, não bastasse era bacharel pela Universidade de Coimbra e já exercera importantes cargos em Portugal e na América, sendo então um eclesiástico de grande prestígio. ${ }^{8}$

O fato é que Garrido julgava necessário esclarecer os motivos por ter dedicado tal impresso. Dava então suas razões:

Tres graòs de Pastoria vi governar os grandes rebanhos deste mundo, quaes são, Mayoraes, Zagaes, e Pastorinhos, e outros tres graòs de Pastores vejo pastorear no mystico rebanho das Ovelhas do Senhor Mayoraes. Os Prelados Eclesiasticos, que governão almas com geral juridição, como V. Excellencia, em todo este Patriarcado, Zagaes. Os Curas, Parochos com jurisdição particular em suas Freguesias, e Pastorinhos são os Mestre de Meninos, que cuidão dos cordeirinhos nos limites de sua Escola. Vendome eu constituído por V. Excellencia, nesta obrigação de pastar tambem ovelhas, que estão a meo cargo, como legitimo Mestre de Meninos, e ouvindo eu ballar estas ovelhas pelo pasto da Doutrina, que he nutrimento das almas, [...] Vendo eu que os parvulos me pedião lhes declarasse miúda, e distinctamente

\footnotetext{
${ }^{8}$ Machado, D. B. (1752). Bibliotheca Lusitana. Historica, Critica, e Cronologica. Na qual se compreende a noticia dos Autores Portuguezes, e das Obras, que compuzerão desde o tempo da promulgação da Ley da Graça até o tempo presente. Tomo III. Lisboa: Na Officina de Ignacio Rodrigues, p. 769.
}

Zetetiké, Campinas, SP, v.29, 2021, pp.1-18 - e021025

ISSN 2176-1744 
neste Livro as duvidas, que por grandes são podia compreender sua curta capacidade, e ouvindo eu exclamar a Deos por seo Profeta Ezequiel sobre os Pastores, que sendo diligentes consigo, são negligentes em pastar suas ovelhas [...] por desempenho de minha obrigação resolvi com grande trabalho, e disvelo descubrir, e preparar (fundado nas contas) este fructifero campo de letras humanas, e Divinas, em que pastassem, e se nutrissem estas novas ovelhas, e cordeirinhos da Igreja com espirituais documentos. E pois he propriedade do bom Pastor, pastar suas ovelhas [...] - aqui ofereço a v. Excellencia como bom Pastor que he no Patriarcado de Lisboa este fértil campo de letras, que pòde servir de bom pasto para todas suas ovelhas (Garrido, 1739, Dedicatória).

Apesar de extenso, o excerto de Taboada Curiosa é extremamente significativo, na medida em que seu autor, um "Mestre de Meninos", descreve como entende o processo de constituição de um infantil, ou como denominou as três formas de governar os rebanhos. Importante destacar que nesse processo, Garrido percebe a prática de instrução da aritmética como forma de educação e de condução das condutas dos infantis. Nesse sentido, o autor associa a prática de aprendizagem dos números com o processo de devoção cristã assumido pelos fiéis católicos.

Ainda antes de iniciar propriamente a primeira parte da obra Taboada Curiosa, e, seguindo a estratégia de aproximar o leitor com elementos cristãos, o autor apresentou em três páginas uma carta escrita pelo Frei João de Nossa Senhora (1701-1758). Tratava-se de uma redondilha ${ }^{9}$ que o cônego português fizera para seu amigo e admirador João Garrido. Frei Nossa Senhora era um popular frade franciscano do Convento de São Francisco de Xabregas em Lisboa. Era famoso por suas aptidões com as rimas. Para Garrido dedicou algumas das seguintes palavras:

Meu grande amigo, e Senhor

João Antonio Garrido.

Em Portugal conhecido

Por famoso contador.

[...]

Hum Livrinho sem cobiça

Me destes, por cousa boa,

Onde vi todo Lisboa

Feita caza de Justiça.

Minha vontade obrigada

Se vê ao que hides dando,

Eu cá tudo vou contando

Pela vossa Taboada.

[...]

Pondes tudo em algarismos

Por numeros tão profundos,

\footnotetext{
${ }^{9}$ Uma redondilha foi o nome dado, a partir do século XVI, aos versos de cinco ou sete sílabas — a chamada medida velha. Aos de cinco sílabas dava-se o nome de redondilha menor e aos de sete sílabas, de redondilha maior. A redondilha foi muito utilizada por poetas portugueses como Luís de Camões e Garcia de Rezende.
} 
Que tudo contaes nos mundos;

No Ceo, na terra, e abysmos

Tudo nos mundos contara

A conta, se mais coubera,

E se mais mundo houvera,

[...]

Singular só como o Sol,

Se lá nasceste Hespanhol,

Sede hoje cá Portuguez.

Deos vos guarde, e vos renove

Com graça n'alma gentil

Quinze de Março de mil

Setecentos trinta, e nove.

O frade português reconhece na figura de Garrido um importante contador espanhol que na cidade de Lisboa fizera notoriedade como mestre de aritmética. Nossa Senhora termina sua redondilha datando a 15 de março de 1739, ano da publicação da segunda edição de Taboada Curiosa. A reimpressão de 1739 continha além das três licenças necessárias - Do Ordinário, Do Santo Ofício e Do Paço -, um Sumário do Privilégio Real. Neste Sumário ficava expresso por ordem da Majestade portuguesa o direito de Joam Antonio Garrido imprimir e vender seu livro Taboada Curiosa, do mesmo modo reconhece o autor como "professor de Arismetica, naturalizado por S. Magestade neste Reyno" (Garrido, 1739).

A aproximação textual que Garrido faz entre saberes aritméticos com elementos da religiosidade cristã pode ser visto a partir de algumas possibilidades estratégicas utilizadas pelo autor. Primeiro, o discurso elaborado por eclesiásticos a Garrido, prestando-lhe desmedidos elogios, conferem-lhe reconhecimento e autoridade como "mestre de meninos", validando também, por toda a Corte, os seus saberes como mestre de aritmética. Tal laudatória eclesiástica era uma forma de converter o discurso do professor de aritmética em um impresso, que ganhava condições de tratado para o ensino e aprendizagem da aritmética. De um modo geral, o tratado de aritmética tinha esse duplo atributo, pois pretendia auxiliar tanto na prática dos mestres que desejam ensinar a importante arte de contar, como os aprendizes, que se valendo das "taboas" poderiam memorizar todas as espécies de conta. E, segundo, pelo fato da educação aplicada nas escolas régias portuguesas do século XVIII estar muito vinculada ao domínio do ler, escrever, contar, rezar e se comportar. Portanto, Garrido seguia os discursos conformadores de uma sociedade que pretendia ser alfabetizada aos moldes dos grandes centros urbanos europeus, mas com a religiosidade e com os comportamentos sociais próprios do seu Reino.

\section{Considerações finais}

Joam Garrido não poupava esforços para descrever a aritmética como uma prática social, tanto que, na medida do possível, buscava conceituar o significado das "cousas" por meio dos principais tratadistas da época. Nas palavras do autor: 
[...] pareceome util, e conveniente para mim, e para todo o contador, fazer esta nova Taboada, consultando primeiro a Calepino, Prosodia, Bluteau, Hortega, Moya, Pereira, e Brito, e mais Authores, que brevemente as regras mais importantes, e pertencentes á conta, que em varios Livros achey distribuídas (Garrido, 1752, Prólogo).

O ensino das definições e dos conceitos de elementos matemáticos mais triviais visava a aprendizagem das grandezas. O ensino das grandezas era o objetivo final de Garrido, "não póde fazer bem toda a conta, sem primeiro saber a definição da conta, pezo, e medida, que são as regras de que consta". Esta proposta de ensino pode ser percebida como uma possível crítica direcionada aos métodos de ensino utilizado por outros mestres, pois "Isto me parece que he ensinar com fundamento; ensinar as partes com tudo, e não ensinar tudo sem partes, como alguns fazem" (Garrido, 1752, Prólogo, p. 5).

Outro elemento paratextual utilizado na obra é a alegação de que o impresso decorre da necessidade dos jovens aprendizes e da petição dos contadores mais iniciantes.

Depois de eu ensinar todas as regras, e contas, que aqui se contêm, a meus discipulos, me pedirão ansiosamente que lhes fizesse hum caderno, ou resumo de todas ellas para renovar a memoria, quando lhes esquecesse; porêm receoso eu de fazer o que não fizeram os outros Mestres desta Corte, e parecendo-me excessivo trabalho, e custo de fazello com a pena a cada hum em particular, sendo para todos mais cõmunicavel e barato, com a impressão; me resolvi fazello assim a rogo de muitos: pois ainda que ha outros muitos, e varios livros, que tratão de conta, não achavão, nem eu achey no idioma Portuguez, quem trata tão clara, e compediosamente desta matéria, como aqui vay apontando com a diffinição do pezo, conta, e medida, com a variedade, e valor das moedas, que correm neste Reyno, e outros da Europa, e com os exemplos de todas as contas tão práticos, e inteligiveis, para guia dos novos contadores, e lembrança dos esquecidos (Garrido, 1752, Prólogo).

Após a primeira edição de Taboada Curisosa ter ganho popularidade e circulação no Reino, a ocorrência de algumas controvérsias na Corte portuguesa parecia condenar o método utilizado por Joam Garrido, bem como pretendiam censurar sua obra. Não obstante, seu autor, também se valeu da escrita paratextual como forma de se justificar e se defender dos ataques que sofria.

Depois de impressa a Taboada Curiosa, a primeira vez com boa aceitação de prudentes contadores e dos melhores Mestres da Corte; veyo a mim o mais mofino [desafortunado] de minha profissão, dizendo que era escuzada tal Taboada, (e julgando a todos por si) que todos sabião isto, que tido se achava nos livros, que aqui não havia cousa nova, e outros desprezos, que não refiro. De tal gente desprezadora me livre Deos a mim e ás minhas obras, pois por estes entendo que disse Christo por S. Matheus cap. 7 a 6 Neque mitatis margaritas vestras ante porcos, ne fonte couculcent e as pedibus suis. Que não deitemos nossas margaritas aos que são, ou tem propriedade de porcos, porque as não desprezem. E assim ao pio Leytor deitarey eu esta minha; porque sómente elle a saberá apreciar, e conhecer meu trabalho, e vontade, que tive de servir a Deos, e à Republica com esta util obra (Garrido, 1752, Prólogo). 
Como foi possível perceber ao longo da presente investigação, a análise de elementos paratextuais não se restringem somente a enunciar o processo educativo que o autor pretendia transmitir. Em Taboada Curiosa a escrita paratextual privilegiou duas sentenças, as quais firmamos neste texto se tratarem de estratégias discursivas utilizadas por seu autor.

A primeira estratégia presente no impresso foi a manifestação de uma rede de sujeitos influentes na Corte portuguesa. Composta por religiosos, tipógrafos, juristas, bem como pelos próprios censores que legitimaram a impressão do tratado de aritmética, a rede de compadrio atestava que Joam Antonio Garrido era um importante "mestre de meninos" que ensinava com enorme perícia o ensino da aritmética. Tal rede ainda possibilitou que o professor espanhol fosse reconhecido por el Rey como de fato um lusitano, prestígio incomum aos imigrantes da época, bem como que Taboada Curiosa fosse impressa e reeditada várias vezes em todo território português.

A segunda estratégia pretendia validar a produção de significados matemáticos por meio da transmissão de conceituações aritméticas (grandezas, contas e medidas) relacionadas com uma vivência em sociedade. Compreendendo que tal sociedade portuguesa estava composta por diferentes elementos de transformação social, econômica e política, distintas condições podem ter garantido o sucesso editorial da obra Taboada Curiosa. A relevância da obra perante seu público consumidor pode decorrer tanto do contexto de venda - nas principais escolas de Lisboa -, como dos discursos nela expresso que exemplificam práticas sociais que se davam em torno do comércio e dos negócios mercantis. Em termos mais precisos, cabe-nos dizer que a aritmética estava associada à necessidade de aritmetizar o real, isto é, perceber numericamente situações da realidade da vida:

A aritmetização e a matematização das situações consistem em elaborar representações simbólicas quantificadas do real e depois em operar (seguindo regras precisas) sobre estas quantificações, para que os resultados das operações (aritméticas) efetuadas sobre as representações simbólicas forneçam uma aproximação aceitável (cujo desejável grau de adequação, para, além disso, terá sido fixado) dos resultados que seriam efetivamente obtidos pela aplicação no real de ações correspondentes às transformações simbólicas (acréscimos, decréscimos, repartições etc.) (Fayol, 2010, p. 13).

Em última análise, as ideias de Joam Garrido relativizam o ensino da aritmética da aplicabilidade do que é real à época. De acordo com o pesquisador português António Augusto Almeida, os livros de aritmética são representativos de seu tempo, suas páginas demonstram os "problemas, soluções, modos de fazer, mas todo aquele mundo e todo aquele tempo é tempo e mundo dos homens que vivem, que nele refletem e agem e agindo transformam" (Almeida, 1994, v. 2, p. 07). Nesse sentido, muitas das instruções são metodologias apresentadas para a autoinstrução na "arte" da "arismetica", que utilizava exemplos práticos, cotidianos para facilitar a compreensão/aprendizagem e ainda, alguns elementos que deveriam ser "decorados", a saber de memória, como por exemplo, o uso de variadas regras. 


\section{Fontes}

Bluteau, R. (1728). Vocabulário Portuguez e Latino, (...). Lisboa: na Officina de Pascoal da Sylva.

Carta Régia de 6 de novembro de 1772. Retirado em 12 de janeiro, 2018, de: http://iuslusitaniea.fcsh.unl.pt/

Figueiredo, M. A. (1722). Nova escola para aprender a ler, escrever e contar. Offerecida á Augusta Magestade do Senhor D. João V. Rey de Portugal. Lisboa Occidental: Officina de Bernardo da Costa de Carvalho, Impressor do Serenissimo Senhor Infante.

Garrido, J. A. (1752 [1739]). Taboada Curiosa, Novamente Reformada, e Augmentada, em que se trata de todas as regras geraes, e especcies de conta [...]. Lisboa: na Officina de Domingos Rodrigues.

Machado, D. B. (1752). Bibliotheca Lusitana. Historica, Critica, e Cronologica. Na qual se compreende a noticia dos Autores Portuguezes, e das Obras, que compuzerão desde o tempo da promulgação da Ley da Graça até o tempo presente. Tomo III. Lisboa: Na Officina de Ignacio Rodrigues.

Silva, A. M. (1789). Dicionario da Lingua Portugueza. Lisboa: Typographia Lacerdina.

Silva, I. F. (1859). Diccionario Bibliographico Portuguez. Aplicaveis a Portugal e ao Brasil. Tomo Terceiro. Lisboa: Na Imprensa Nacional.

Villeneuve, D. J. R. (1767). A aia vigilante, ou reflexões sobre a educação de meninos, desde a infancia até á adolescência. Lisboa: Offic. de António Vicente da Silva.

\section{Referências bibliográficas}

Adão, Á. (1997). Estado Absoluto e ensino das primeiras letras. As Escolas Régias (17721794). Lisboa: Fundação Calouste Gulbenkian.

Almeida, A. A. M. (1994). A aritmética como descrição do real (1519-1679). Contributos para a formação da mentalidade moderna em Portugal. Lisboa: Imprensa Nacional-Casa da Moeda, (2 volumes).

Amaral, G. L., \& Ripe, F. (2017). Os primeiros rudimentos de aritmética que deve saber o menino cristão: análise de um tratado pedagógico publicado na Bahia no ano de 1813. POIÉSIS, 11, 249-267.

Arredondo, M. S., Civil, P., \& Moner, M. (2009). Paratextos em la literatura española (siglos XV-XVIII). Madri: Casa de Velázqvez.

Chartier, R. (1998). A ordem dos livros: leitores, autores e bibliotecas na Europa entre os séculos XVI e XVIII. Brasília: UnB.

Dassie, B. A. (2020). Paratextos editoriais e História da Educação Matemática: uma leitura de livros didáticos. Actas do Congresso Ibero-americano de História da Educação Matemática (pp. 188-196), Covilhã. Lisboa: UIED. Retirado em 10 de janeiro, 2020, de: http://www.apm.pt/files/177852_C11_4dd7a3d450d31.pdf 
DOI: $10.20396 /$ zet.v29i00.8661083

Fayol, M. (2010). Fazer operações e resolver problemas - reflexões relativas ao ensino da aritmética. In M. Fayol; A. Toom; A. Bivar; L. M. Aires (Eds.), Fazer contas ajuda a pensar? Portugal: Porto Editora/Fundação Francisco Manuel dos Santos.

Foucault, M. (2012). A ordem do discurso: aula inaugural do Collège de France, pronunciada em 2 de dezembro de 1970. São Paulo: Edições Loyola.

Genette, G. (2009). Paratextos editoriais. Cotia, SP: Ateliê Editorial.

Hébrard, J. (1989). La escolarización de los saberes elementales en la época moderna. Revista de Educación, 288, 63-104.

Morais, J. (2011). A aprendizagem dos sistemas simbólicos dos fonemas e das quantidades numéricas: semelhanças, diferenças e relações. In N. Crato (Org.), Ensino de matemática: questões e soluções. Lisboa: Fundação Calouste Gulbenkian.

Orlandi, E. P. (1999). Discurso e leitura. São Paulo, Cortez; Campinas: Editora da Universidade Estadual de Campinas.

Ripe, F. (2017). "Fez Deos tudo com numero, peso, \& medida": sobre práticas educativas em um tratado que ensina aritmética em Portugal do século XVIII. Revista de História e Historiografia da Educação, 1(2), 145-166.

Souza, E. S. (2004). A prática social do cálculo escrito na formação de professores: a história como possibilidade de pensar questões do presente. Tese de doutorado. Universidade Estadual de Campinas, Faculdade de Educação. Campinas: UNICAMP, $284 \mathrm{f}$.

Valente, W.R. (2005). A matemática na escola: um tema para a história da educação. In D. Moreira; J. M. Matos (Orgs.), História do ensino da matemática em Portugal (pp. 2132) Lisboa: Sociedade Portuguesa de Ciências da Educação. 